\title{
Criterios \\ La inmodélica gestión de la arqueología en España: de servicio público a mercancía
}

Julio M. Vidal Encinas

Arqueólogo Territorial. Servicio Territorial de Cultura de León. Junta de Castilla y León

\section{Resumen}

El autor reflexiona sobre la drástica modificación del marco administrativo y científico que ha experimentado la Arqueología en nuestro pais en los últimos años. La profesión ha diversificado su práctica y ha abandonado su casi exclusiva circunscripción al ámbito académico universitario. Las excavaciones arqueológicas pierden su componente esencialmente público para pasar al ámbito privado y la preocupación por las investigaciones rigurosas cede ante la inquietud por la conservación de los restos. En este contexto ¿ejerce la administración las responsabilidades que le competen por imperativo legal?

\section{Palabras clave}

\section{Gestión}

Arqueologia

España

Patrimonio arqueológico
"En el contexto liberal que domina en la Unión Europea, Francia se ha distinguido por reconocer que la Arqueología tiene la misión de constituir un servicio público. Un fracaso abriria ciertamente la puerta al ejercicio privado de dicha misión, tal y como está sucediendo en la mayor parte de los países de nuestro entorno" (Editorial de Les Nouvelles de I'Archéologie, $n^{\circ} 86,4^{\circ}$ trimestre 2002)

"...y las Empresas de Arqueologia, una nueva realidad importante, que debe alegrarnos, ya que representan un auténtico boom del ejercicio liberal de la profesión; como su propio nombre indica, están orientadas a la búsqueda de unos beneficios a través del ejercicio de la profesión arqueológica, todo lo cual es absoluta y perfectamente legitimo" (Palabras de G. Ruiz Zapatero en su intervención en la Mesa Redonda: Los Inventarios al servicio de la Gestión e Investigación Arqueológicas. En: A. Jimeno Martínez, J. M. del Val Recio y J. J. Fernández Moreno (Eds.) Inventarios y Cartas Arqueológicas. Homenaje a Blas Taracena. Junta de Castilla y León. Soria, 1993, p. 255)

En los últimos años hemos asistido a una drástica modificación del marco administrativo y científico en el que se venía ejerciendo la Arqueología en nuestro país. Un cambio verdaderamente sustancial que ha alterado radicalmente el ejercicio de esta profesión y que, a pesar de su trascendencia, ha pasado, en buena parte, desapercibido; no en vano, por ejemplo, nunca ha sido objeto de debate público alguno, monográfico, entre los mismos arqueólogos, a pesar de afectar tan profundamente al sentido y papel que la Arqueología tiene en el seno de nuestra sociedad. Es más, contadas han sido las voces que se han alzado en contra de los derroteros por los que empezaba a deambular la profesión. Muchos de los que lo hicieron, por otra parte, parecian más preocupados en defender exclusivos intereses corporativos que en denunciar, por ejemplo, el papel cada vez más alejado del sentido intelectual que siempre ha prevalecido en la disciplina, frente a la "mercantilización" que ahora domina su práctica en España.

En efecto, la manifestación más notable de todo ello ha sido la conversión de la excavación arqueológica en una "obra", desprovista ya, en gran medida, del contenido que como "proyecto de investigación" siempre tuvo, y, con ello, la transformación del arqueólogo -por causa de los nuevos horizontes profesionales que el "mercado arqueológico" abría- en un profesional "libre", junto con la aparición de innumerables empresas de arqueología. Todo ello al socaire de la multiplicación hasta el infinito de las intervenciones arqueológicas, especialmente en el ámbito de los Conjuntos Históricos -la mal llamada "Arqueología Urbana"-, y en el dominio de las Obras Públicas.

La Arqueología, por lo tanto, ha dejado de ejercerse exclusivamente en los ámbitos académicos y ha pasado a convertirse en una actividad más en la esfera de las "empresas de servicios", ligada al "mercado" y, en consecuencia, a las "leyes de la oferta y la demanda". Una manifestación bien significativa de todo ello es que, incluso, desde el punto de vista de algo tan sumamente intencional como es el lenguaje, la misma "excavación arqueológica" ha dejado de denominarse tal para llamarse "obra", la cual, asimis- 
mo, es objeto de libre competencia -como cualquier otra, una carretera, un alcantarillado, etc.-, lo que quiere decir que puede ser "licitada" o "subastada" al mejor postor, quien, a veces, es, simplemente, el que se propone hacerla de la manera más barata. Las estratigrafias se "cubican", midiéndose, por lo tanto, en metros cúbicos para su excavación arqueológica, en función de unos rendimientos estimados. Y ésta hasta se "subcontrata"; no sólo su "ejecución material" -la mano de obra, instalaciones, etc.-, sino también la misma dirección técnica, cuya virtualidad, en muchos casos, es comparable a la de un simple capataz que está al frente de una cuadrilla de obreros destajistas ¿Qué ha sucedido en nuestro pais para que estos cambios tan sustanciales se justifiquen porque son "legítimos"? Y, lo que es verdaderamente importante, ¿ha mejorado, de forma proporcional al número, extensión y presupuesto involucrado en las excavaciones, el ejercicio profesional de la Arqueología y sus aportaciones científicas al conocimiento histórico?

Circunscrita desde sus orígenes, de forma casi exclusiva, al ámbito académico universitario, esta profesión ha visto cómo se diversificaba notablemente su práctica como consecuencia de las necesidades surgidas desde diversas instancias de carácter público -Comunidades Autónomas, Ayuntamientos, etc.-, cada vez más preocupadas de los aspectos relacionados con la protección del patrimonio arqueológico, tradicionalmente abandonado a su suerte. No es en modo alguno casual que tal preocupación estuviera muy ligada a la llegada de la Democracia en España y a la misma configuración administrativa del Estado, que otorgó responsabilidades de gestión en esferas territoriales muy cercanas al ciudadano. Tal nueva situación dio lugar a la aparición de novedosas normativas y controles que, por imperativo legal, se impusieron -particularmente, en las Obras Públicas y en los Conjuntos Históricos-, como consecuencia del traspaso de unas competencias que inicialmente eran ejercidas por el Estado. Los nuevos cambios modificaron sustancialmente el estatuto profesional de los actores que protagonizaban la función: los que dirigían las excavaciones arqueológicas dejaron de ser arqueólogos unidos a la Universidad u otros ámbitos -pocos- de carácter público, para convertirse en profesionales libres o empresas de Arqueología, nacidos al socaire de la espectacular multiplicación que tiene lugar en el número de las intervenciones arqueológicas.

Parece realmente sorprendente que un cambio tan sustancial y profundo haya pasado prácticamente desapercibido, sobre todo por la falta de respuesta que, creemos, debería haber recibido desde los, hasta entonces, destinatarios naturales de las excavaciones arqueológicas -la Universidad-.

Además, desde una perspectiva que atañe al terreno de lo social asombra que un servicio que hasta entonces tenía un componente esencialmente público pasara inopinadamente al ámbito privado -con las negativas consecuencias que más adelante veremos-, sin que nadie reclamara a la Administración el ejercicio de una responsabilidad que le compete por imperativo legal.

La Arqueología, pues, en tales ámbitos territoriales, adquirió una relevancia hasta entonces desconocida, causada por las urgentes necesidades de conservación -que no investigación- de los yacimientos arqueológicos, secularmente condenados, las más de las veces, a la destrucción pura y simple. Incluso, a veces, entre los mismos arqueólogos, existe una mayor preocupación por la conservación de unos restos, que por su investigación competente y rigurosa, cuando, esta última, constituye el principal acto de conservación en Arqueología: en muchos de los conflictos que se han producido en los últimos años en España, que han tenido a la Arqueología como protagonista, ha existido más preocupación por el hecho de la conservación a macha martillo de los restos, que por su real conocimiento científico.

Por lo tanto, la primera preocupación de aquellos nuevos instrumentos administrativos fue la de dar respuesta a la carencia de medidas de protección, particularmente por medio de la adopción de políticas preventivas hacia el Patrimonio Arqueológico, especialmente en el terreno ya señalado de la Arqueología Urbana y el de las Obras Públicas. Ello ha dado lugar a la llamada "Arqueología de Gestión", la cual, impulsada por las Comunidades Autónomas, se ha convertido en práctica preeminente, auténtico fin en sí misma, destinada a "documentar" los yacimientos arqueológicos amenazados, para permitir el desarrollo de los proyectos que los ponían en peligro y que, a la postre, acababan destruyendo. La excavación arqueológica, por lo tanto, se ha convertido en un auténtico acto de exorcismo, destinado a neutralizar y eliminar el componente arqueológico que interfería en las obras públicas o privadas. Ya no se miraba para otro lado cuando aparecian restos arqueológicos, sino que se arbitraban medidas para "documentarlos", tarea que se encomienda -a veces sin apenas intervención de la misma Administración Pública- a tales profesionales libres o empresas. La excavación arqueológica -con todo su rosario de paralizaciones, tramitaciones, costes e incertidumbre que generaejemplifica de la mejor manera posible las dificultades, impedimentos o interferencias que la salvaguarda del Patrimonio Histórico puede tener, sólo equiparable a lo que sucede entre las Obras Públicas y la Arqueología, ámbitos en los que, insistimos, no puede mostrarse con mayor dramatismo el conflicto entre la necesidad y obligación de preservar el pasado histórico y necesidades y obligaciones no menos justificadas, como son la construcción de pantanos o autovías, por ejemplo.

La excavación arqueológica, en consecuencia, es vista -especialmente por la propia Administración- como un problema, más que como esa vistosa y apasionante actividad que, a veces, ciertas campañas propagandísticas propalan; no en vano, constituye un nuevo trámite que hay que cumplimentar, pero que, además, llena de incertidumbre al mismo propósito constructivo, en virtud de la pre- 


\section{Criterios}

La inmodélica gestión de la arqueología en España: de servicio público a mercancía

\section{Julio M. Vidal Encinas}

gunta que cualquier propietario o constructor se puede hacer: ¿Y si aparece algo que me impide construir? Eterna tesitura que acongojaba sus cabezas en otros tiempos, pues tal miedo ha sido ya prácticamente desterrado por la cotidiana demostración de que la Arqueología no impide a nadie construir. Pero, eso sí, cuesta dinero, y lleva tiempo, hasta el punto que, en muchos casos, se sabe cuando empieza una excavación, pero no cuando va a terminar, lo que entorpece penosamente los planes previamente establecidos.

El asunto del dinero a nadie se le puede escapar, por razones obvias, porque ¿quién tiene que pagar las excavaciones arqueológicas? ¿El que promueve las obras? ¿La Administración competente en la protección del Patrimonio Histórico? La respuesta a tal pregunta parece clara desde el punto de vista legal, por cuanto la Ley de Patrimonio Histórico Español establece nítidamente la responsabilidad de los poderes públicos a la hora de garantizar la conservación del Patrimonio Arqueológico, un mandato que emana de la misma Constitución Española, la cual señala en su artículo 46 que Los poderes públicos garantizarán la conservación y promoverán el enriquecimiento del patrimonio histórico, cultural y artístico de los pueblos de España y de los bienes que lo integran, cualquiera que sea su régimen jurídico y su titularidad.

Aún más, la Ley 16/1985 de Patrimonio Histórico Español considera bienes de dominio público los objetos arqueológicos que aparezcan en cualquier circunstancia, incluidos, por supuesto, los que provienen de excavaciones oficiales, las cuales pueden ser ordenadas por la Administración en cualquier terreno público o privado, circunstancia que se repite en toda la legislación de naturaleza autonómica.

Sin embargo, la respuesta a la pregunta de quien tiene la obligación de costear una excavación arqueológica creemos que tiene fácil contestación, por cuanto las Administraciones Públicas han demostrado, de forma prácticamente unánime y generalizada, su nula intención de recurrir a sus presupuestos para llevar a cabo una excavación arqueológica en un Conjunto Histórico o en una obra pública. Y lo curioso es que, para tal propósito, han contado con la inestimable ayuda de los propios arqueólogos; no en vano, tanto se enfatizó, en los comienzos de la "Arqueología de Gestión", en el hecho de que las excavaciones fueran asumidas por los mismos promotores o adjudicatarios -auténticas "bestias negras"-, de obras privadas o públicas, que amenazaban al patrimonio, emulando lo que es doctrina en el terreno del Medio Ambiente: "el que contamina paga". Cuando es notorio que ninguna excavación arqueológica es sufragada por promotor inmobiliario alguno -la paga el que adquiere la vivienda que se construye-, o por la gran empresa de obras públicas -que la endosa a la Administración Pública en las consiguientes modificaciones presupuestarias por situaciones imprevistas en el desarrollo del proyecto-.

En efecto, actualmente una buena parte -por no decir todas- de las excavaciones arqueológicas que se realizan en un Conjunto
Histórico, por ejemplo, son financiadas por los promotores privados de nuevas edificaciones, lo que es interpretado por muchos de ellos como una especie de salvoconducto para construir. Es decir, se paga la excavación a cambio de que se le esterilice el solar de cualquier virus arqueológico, como si de un exorcismo o de un antibiótico se tratara. Porque lo cierto es que ninguno de ellos se ha convertido, de la noche a la mañana, en benévolo patrocinador del trabajo arqueológico -carencia que, por lo demás, tampoco nadie les reprocha-, puesto que el coste de la excavación se va a añadir o repercutir en el precio final de la vivienda, aumentándolo en la parte que corresponda. A este escenario se ha llegado por causa de la resistencia de la propia Administración a asumir tales costes, dando lugar a farragosas y desesperantes tramitaciones administrativas, que llenaban de incertidumbre las inversiones de los promotores. La situación que se crea entre éstos, derivada del "o lo tomas o lo dejas", sólo tiene dos alternativas: o bien pagar la excavación arqueológica para continuar con el proyecto de construcción, o bien abandonar la intención de construir, con lo que ello supondría. Ni que decir tiene que todos han elegido el primer supuesto, que desbloquea el problema arqueológico de forma inmediata y que no causa, las más de las veces, quebranto económico alguno.

Me parece necesario llamar la atención sobre el hecho siguiente: una parte sustancial de los solares de un Conjunto Histórico tiene unas dimensiones pequeñas, lo que constriñe la dimensión de las promociones inmobiliarias, restringidas también por las normas que limitan la altura de la edificación, con objeto de proteger el aspecto del conjunto. Por lo tanto, la repercusión que tiene el coste de las intervenciones arqueológicas es más importante cuanto menor es el tamaño del solar, lo que quiere decir que la financiación de las excavaciones arqueológicas es asumida por promociones inmobiliarias de pequeña escala, convirtiéndose, de hecho, en un inédito impuesto indirecto más. En definitiva que, en este ámbito, la salvaguarda del patrimonio arqueológico recae en la economía de quien va a comprarse una vivienda y no de los presupuestos públicos.

Pero detrás de esta situación se encuentra otra que, en nuestra opinión, es mucho más grave y preocupante. En efecto, si, como he tratado de exponer, no existe amparo legal alguno para la obligación que establece la Administración de que el coste de una excavación tenga que ser asumido por el que promueve o construye una nueva edificación -existen dos sentencias del Tribunal Superior de Justicia de Galicia que dan la razón a los promotores que pagaron la excavación frente a la Administración, que no cumplió con su obligación-, lo que verdaderamente inquieta es, por una parte, lo que ello supone de abandono de obligaciones establecidas en la misma ley, y, por otra, lo que significa de privatización de la Arqueología, o, lo que es lo mismo, la pérdida de la misión que como servicio público tiene. Ello se puede atisbar en el hecho de que quien paga es el que pone también el director técnico de la excavación, el cual es buscado en el mercado y con los criterios que éste marca, a saber: 
Gráfico 1. Inversiones, en millones de pesetas, realizadas por la Junta de Castilla y León en el patrimonio arqueológico años 1992-2002 (Fuente: Junta de Castilla y León)

Gráfico 2. Excavaciones e investigaciones arqueológicas y paleontológicas subvencionadas por la Junta de Castilla y León. Años 1992-1999. A partir de este año desapareció la convocatoria pública de subvenciones (Fuente: Junta de Castilla y León) (en millones de pesetas).

quien más barato presupuesta el trabajo -como si de una subasta en una Ionja cualquiera se tratara- será el adjudicatario del mismo, obviando los criterios de idoneidad, conveniencia, profesionalidad e interés científico, que son consustanciales a la atribución de cualquier dirección técnica en Arqueología, que es, sobre todo, responsabilidad científica. Ello porque la excavación arqueológica preventiva ha dejado de ser un proyecto investigador, una fuente de investigación, para pasar a convertirse en una simple actividad económica, como cualquier otra, y su tratamiento por parte de la Administración un trámite más, embarazoso y molesto, que lo único que hace es retrasar las obras y, con ello, sus "plazos de ejecución", además de aumentar los presupuestos económicos. Por ello, lo único que realmente le preocupa es la agilidad mal entendida, a saber, tramitar con la mayor urgencia la solicitud de permiso de "seguimiento" o excavación arqueológicos -puesto que sale gratis-, en detrimento, muchas veces, de un programa o proyecto de intervención sólidamente establecido, tanto en sus objetivos como en los medios necesarios para llevarlos a cabo.

Esta situación tiene su colmo particular de perplejidad, por ejemplo, en la falta de respeto a la unidad de la investigación que toda intervención arqueológica exige, es decir, que sea el mismo arqueólogo que la ha iniciado el que la continúe, cuando se tiene que realizar en varias fases. Despropósito que la Administración no sólo no trata decididamente de evitar, sino que muchas veces promueve: como una excavación arqueológica es algo así como levantar una tapia de ladrillos -algo, por lo tanto bien alejado de preocupaciones intelectuales-, poco importa quién la continúa, cuando se realiza por fases. Lo único importante es que quien tome las riendas sea arqueólogo: si lo propone la misma empresa implicada en el proyecto de obras, quien le va a pagar en definitiva, no se le va a decir que no, cuando no cuesta dinero. Cuando lo hace la misma Administración lo que cuenta, a veces, es que sea más barato que cualquiera, incluido el presupuesto que pueda ofrecer el que comenzó dirigiendo excavaciones en el sitio.

Esta situación es francamente inaceptable, precisamente, en los Conjuntos Históricos, ya que, ¿por qué concurren tantos directores de excavación como solares existen en él? ¿No se trata, a fin de cuentas, del mismo yacimiento arqueológico? ¿La ciudad romana 0 medieval, pongamos por caso, no es la misma en uno y otro solar? Entonces, ¿su investigación no debería proceder de un único proyecto, realizado bajo la misma dirección científica?

Pero tengo que insistir en este último aspecto, que me parece primordial: la dirección técnica de una excavación arqueológica y su nombramiento. No parece muy necesario extenderse sobre la importancia que tal asunto tiene para llevar a buen término cualquier proyecto de investigación. Y, habida cuenta de la especialización cada vez más creciente que existe dentro de la Arqueología -por los variados dominios culturales y técnicas que tiene que afrontar-, parece una verdad de perogrullo que no todos los arqueólogos tienen

\section{Gráfico 1}

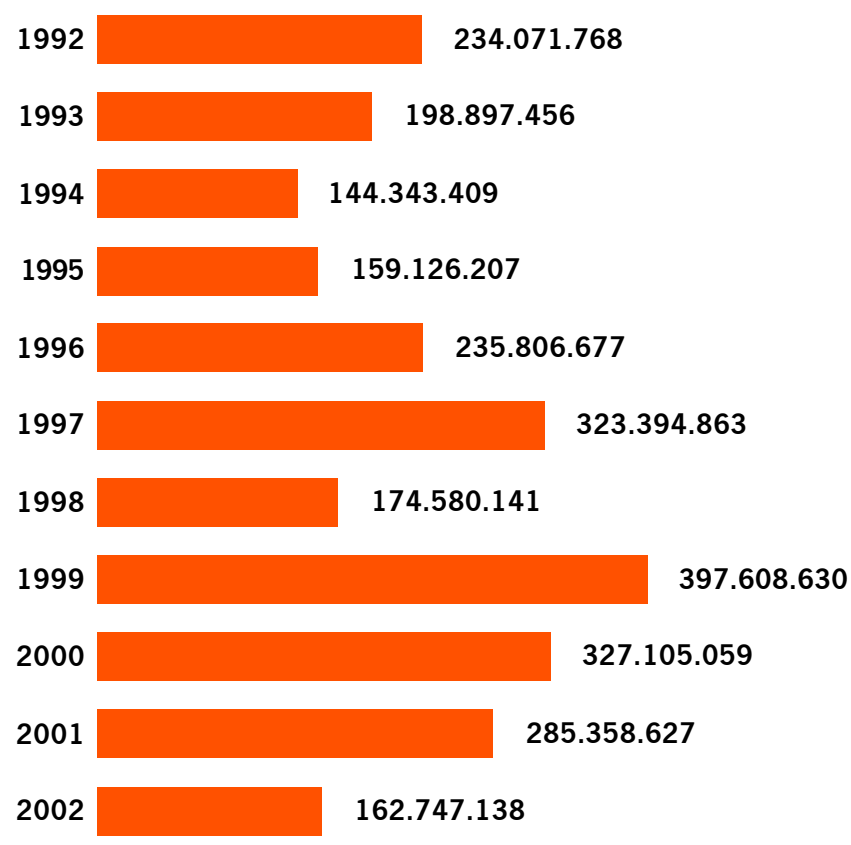

\section{Gráfico 2}

1992

57.000 .000

1993

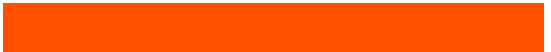

56.000 .000

1994

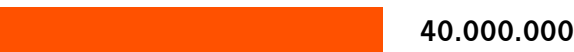

1995

41.500 .000

1996

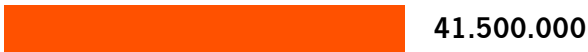

1997

29.881 .000

29.000 .000

1998

27.175.000

1999

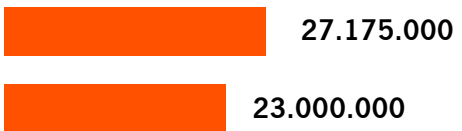

las mismas aptitudes para desafiar cualquier tipo de excavación o período histórico. La misma Ley de Patrimonio ya citada alude a estos aspectos, puesto que indica que los trabajos estarán planteados y desarrollados conforme a un programa detallado y coherente, que contenga los requisitos concernientes a la conveniencia, profesionalidad e interés científico. Trabajos sobre los que, no en vano, la Administración establece la obligatoriedad de una autori- 


\section{Criterios}

La inmodélica gestión de la arqueología en España: de servicio público a mercancía

\section{Julio M. Vidal Encinas}

zación administrativa previa, ejerciendo sobre ellos, además, por su misma condición de interés público o social, tareas de inspección y control, para comprobar que se llevan a cabo de acuerdo con las condiciones en que fueron aprobados.

Entonces, en este contexto, ¿cómo entender que al director de una excavación arqueológica lo proponga, por ejemplo, la empresa constructora de un solar o de tal o cual autovía? ¿Qué sabe tal empresa de idoneidades profesionales y científicas? Parece claro que nada, pero ello no constituye el único aspecto, cuando menos chocante, de la situación que se plantea al permitir tal iniciativa. Indudablemente, lo verdaderamente inquietante es que quien es parte interesada en el proceso -el constructor o promotor-, sea el que designe y pague al director de la excavación arqueológica, causa y efecto de una situación anómala cuya virtualidad admite la Administración, pues así no tiene que destinar recursos presupuestarios a tales tareas.

Sin embargo, es inevitable que, en una situación tal, surjan temores en relación con la real independencia intelectual del arqueólogo, por cuanto es asalariado de quien tiene como objetivo exclusivo, además de construir, hacerlo cuanto antes. Irremediablemente, quien tiene prisa, se la transmitirá a quien, al fin y al cabo, no deja de ser un empleado, el cual, en el marco de las relaciones de mercado que se han establecido, tratará de atender bien a su cliente. $Y$ esto último puede traducirse en concesiones que, en algunos casos, corren el riesgo de menoscabar la calidad del trabajo arqueológico; no en vano, tal cliente no tiene que serlo sólo para una contratación puntual, sino que lo puede ser para muchas otras más, caso de una empresa constructora importante, por ejemplo.

No parece aceptable que el director de una excavación tenga que tener encima, permanentemente, al encargado de la empresa 0 al mismo empresario que promueve unas pocas viviendas en un Conjunto Histórico, o a la gran empresa multinacional adjudicataria de una autovia: en ambos casos van a tratar, por ser su papel natural, de defender sus intereses, que no coinciden en modo alguno con los del arqueólogo que dirige la molesta intervención que paraliza y complica sus obras. ¿Cómo van a entender aquéllos que, surgida la necesidad científica, sea necesario ampliar la excavación en una zona de las obras y que, además, deba realizarse por finos decapados? Algo que ampliaría los plazos de la paralización, al mismo tiempo que encarecería aún más la intervención arqueológica. Por ello, en muchos casos, el director de la excavación suele evitar un pronunciamiento sobre las reales necesidades que tiene para completar su trabajo, para no entrar en conflicto con el empresario que le paga, abandonando su papel natural en todo trabajo investigador y haciéndole perder buena parte de su condición intelectual. En definitiva, desnaturalizándolo, si se me permite el empleo de esta expresión, haciéndole perder, en definitiva, su independencia intelectual.
Tal situación no se produciría si la dirección de una excavación arqueológica fuera atribuida, desde el primer momento en que se plantea el problema, por un Organismo Público, por quien tiene que proporcionar o auspiciar un auténtico servicio público, lo que evitaría situaciones indeseables de presión, defendiendo únicamente intereses intelectuales, de tal manera que las únicas cuentas a rendir fueran de este último carácter y a quién encomienda tal dirección y a sus servicios de inspección.

Para establecer una gestión eficaz de algo tan complejo como es la Arqueología es preciso, primeramente, que se produzca una profunda reflexión y acercamiento entre todos los sectores implicados acerca de los problemas a resolver y los objetivos que se pretende alcanzar. Tales sectores no son otros que, por un lado, el mundo académico e instituciones relacionadas con la investigación arqueológica, y, por otro, la Administración Pública, que tiene el primer lugar por responsabilidad y competencias. Los problemas a resolver parecen obvios: la salvaguarda del patrimonio arqueológico y su compatibilidad con las tareas obvias de necesaria renovación de las infraestructuras que cualquier sociedad moderna exige, mirando hacia atrás, pero también haciéndolo hacia el futuro. Por lo tanto, la primera acción conservacionista que debe asegurarse por parte de todos es la excavación arqueológica solvente y rigurosa, lo cual quiere decir que no puede consistir en un mero sondeo-trámite para pasar página y liberar el terreno, sino que tiene que tener autonomía para poder convertirse en verdadero proyecto de investigación, especialmente cuando la evaluación previa de su potencial científico lo justifique plenamente. Algo, por lo demás, prácticamente común a toda excavación arqueológica. Ésta tiene que ordenarse en un marco de naturaleza legal que obligue a todos, que señale las responsabilidades de cada cual y que proporcione también garantías para que todos los intereses se vean respetados en pie de igualdad. Ello quiere decir, por ejemplo, que se marquen plazos para las actividades arqueológicas y que se proporcione a éstas medios adecuados para cumplirlos. Al mismo tiempo, todo ello debe gestionarse desde un Organismo Público, financiado gracias a las aportaciones que realizan todos los sectores implicados, y, especialmente, la propia Administración, asegurando, por ejemplo, la realización de las memorias de excavación desde planteamientos investigadores y no desde ópticas que reflejan más bien la resolución de un mero trámite administrativo; que exista una dirección única de las excavaciones arqueológicas que se llevan a cabo en un mismo yacimiento -caso de las ciudades-, rodeada de un equipo permanente, organizado en un proyecto de investigación solvente, avalado y encuadrado preferiblemente desde instancias académicas -universitarias, por ejemplo-, que tenga como objetivo el estudio global de la ciudad en el espacio y el tiempo. Finalmente, que se tenga en cuenta la publicación de tales memorias como uno de los objetivos primordiales de cualquier excavación arqueológica. 